\title{
Interaction between adsorbed molecules and tailor made large chelating ligands grafted on SBA-15 studied by means of thermoporometry
}

\author{
Agnieszka Węgrzyn $^{\mathrm{a}, *}$, Marcelina Radko $^{\mathrm{a}}$, Dorota Majda ${ }^{\mathrm{a}}$, Wojciech Stawiński ${ }^{\mathrm{b}}$, Michał Skiba ${ }^{\mathrm{c}}$, \\ Dariusz Cież $\dot{\mathrm{a}}^{\mathrm{a}}$ \\ ${ }^{a}$ Faculty of Chemistry, Jagiellonian University, ul. Gronostajowa 2, 30-387 Kraków, Poland \\ ${ }^{\mathrm{b}}$ REQUIMTE, LAQV, Instituto Superior de Engenharia do Porto, Instituto Politécnico do Porto, Rua Dr. António Bernardino de Almeida 431, 4200-072 Porto, Portugal \\ ${ }^{\mathrm{c}}$ Jagiellonian University, Institute of Geological Sciences, Department of Mineralogy, Petrology and Geochemistry, ul. Gronostajowa 3a, 30-387 Kraków, Poland
}

\author{
Keywords: \\ Mesoporous SBA-15 adsorbents \\ Organic functionalization \\ Thermoporometry \\ Heavy metal ions \\ Organic dyes
}

A B S T R A C T

\begin{abstract}
Modified mesoporous silicas were examined as adsorbents for efficient removal of model pollutants from wastewaters. Functionalized SBA-15 materials for capture of cationic pollutants such as metal cations and anionic dyes were obtained using post-synthesis grafting method. Large organic ligands containing acetyloacetone, 2aminopyridine, 2-aminothiazole and 2-aminobenzothiazole groups were incorporated into the adsorbents' structure. The adsorption capacities reached levels of 38.6, 43.1, 64.3, 68.6 and $88.9 \mathrm{mg} \mathrm{g}^{-1}$ for Cu$^{2+}$, Rose Bengal, Congo Red, Levafix Amber CA gran and Methyl Orange, respectively. Moreover, the adsorption efficiency depended on a type of the model molecule and a type of the surface chelating group. The pores' size and the pores' volume of the hybrid materials before and after adsorption was determined in hydrated state using thermoporometry. For the first time, by means of this methodology, it was possible to propose a model of interactions between the adsorbed molecules and the grafted organosilanes. Adsorption of organic dyes resulted in most cases in formation of J-aggregates.
\end{abstract}

\section{Introduction}

Toxic organic and inorganic chemicals are discharged every day into water, air and soil, severely contaminating the environment [1]. The removal of hazardous pollutants from the environment is an issue of the utmost importance and many methods such as reverse osmosis, ion exchange, precipitation or adsorption have been investigated lately to resolve it $[2,3]$. Adsorption, however, seems to be the best for that purpose and it is widely used due to its low cost, ease of operation and high effectiveness $[4,5]$.

Dyes are common pollutants discharged in substantial amounts by various industries as textile, paper, leather, foodstuffs, rubber and plastics. They are also commonly used as chemical intermediates in the cosmetic and pharmaceutical production. Dyes, may exhibit a toxic, carcinogenic or allergic effect to humans and animals. Compounds such as Rose Bengal, Congo Red and many other are resistant to oxidation, heat and biological degradation [4-6]. Heavy metals are found among the most common pollutants and often accompany dyes in wastewaters. Their release into the environment originates mainly from chemical manufacturing, painting, mining operations, extractive metallurgy, alloy and batteries industries. They have bioaccumulative nature and are non-biodegradable and highly toxic to many life forms.

The adsorbents used in the adsorption techniques should be efficient and sustainable thus research on this topic has been getting considerable attention recently [7]. Wide range of materials such as activated carbons, zeolites, modified clays, polymeric resins and fly ash have been applied in this process [8-11]. However, mesoporous silica (e.g., MCM-41 or SBA-15), has been proved highly effective for removal of various compounds from aqueous solutions due to its high surface area, ordered structure, well-defined pore size, well-defined properties and good chemical, physical and mechanical properties [12-14]. Moreover, it can be modified by organo-functional ligands, what influences its binding strength with selected metal ions and consequently increases adsorption capacities $[15,16]$. Amino-functionalized SBA-15 was found efficient in removal of various metal ions such as $\mathrm{Cu}^{2+}, \mathrm{Pb}^{2+} \mathrm{Cd}^{2+}$, $\mathrm{Co}^{2+}, \mathrm{Zn}^{2+}, \mathrm{Ni}^{2+}, \mathrm{Cr}^{3+}$ and $\mathrm{Al}^{3+}$ [17-19]. Moreover, Wu et al. [20] noted that amino-, diamino-, triamino-functionalized silicas may adsorb anionic dyes such as Acid Fuchsine and Acid Orange II, the dye Reactive Blue-15 was adsorbed with high efficiency on SBA-15 modified with 3aminopropyltriethoxysilane and anchored triethylenetetramine [21]. Mono-, di- and triamine/ammonium functionalized mesoporous SBA-15 selectively adsorbed Malachite Green and Bromothymol Blue at

\footnotetext{
* Corresponding author.

E-mail address: wegrzyn@chemia.uj.edu.pl (A. Węgrzyn).
} 
different pHs ranges [22].

The present work describes interactions of model molecules with functionalized SBA-15 obtained by post-synthesis grafting method, containing the following organic ligands: acetylacetone, 2-aminopyridine, 2-aminothiazole and 2-aminobenzothiazole. To verify the adsorption efficiency of the synthesized materials, they were contacted with solutions of metal cations $\left(\mathrm{Cu}^{2+}\right)$ and organic anionic dyes: Rose Bengal (RB), Congo Red (CR), Methyl Orange (MO) and Levafix Amber CA gran (AMB). The adsorbates were characterized by different geometry, structure, charge density and molecular weight. Thermoporometry was used for characterization of the fresh and spent materials in their unaltered hydrated forms, what allowed to evaluate arrangements of the organic ligands and their interactions with the model pollutant molecules. Thermoporometry (TPM) bases on the fact that a fluid confined in pores of a solid material exhibits a shift in its liquid to solid transition temperature $(\Delta \mathrm{T})$ that is proportional to the size of the pores in which the liquid is trapped. In the standard TPM experiment the sample of a porous material is soaked in the liquid medium, whose melting or crystallization profiles are measured with differential scanning calorimetry (DSC). Water is the most commonly used liquid probe, especially for examining the hydrated materials which can collapse or change their properties during drying or evacuation, therefore proposed method is well suited to study samples used in technology developed for wastewater remediation.

Although several organo-modified SBA-15 materials have been studied for adsorption of metals cations and organic molecules, to the authors' best knowledge, reports regarding large ligands are limited or not available. Moreover, in-depth studies on the interactions of adsorbed molecules with grafted functional groups by characterization technique such as thermoporometry have not been performed so far.

\section{Experimental}

\subsection{Synthesis procedure}

Mesoporous silicas, SBA-15 (sample A or sample B), modified with large organic ligands (acetylacetone (AcAc), 2-aminopyridine (AmPy), 2-aminothiazole (AmS), 2-aminobenzothaziole (AmBenS)) were synthesized according to the following procedure:

- SBA-15 mesoporous silica was obtained by condensation of tetraethylorthosilicate (TEOS) for $20 \mathrm{~h}$ at $45^{\circ} \mathrm{C}$ in the presence of Pluronic P123 dissolved in $\mathrm{HCl}(2 \mathrm{M})$,

- two portions of the silica were additionally aged at $90^{\circ} \mathrm{C}$ for $24 \mathrm{~h}$, either stirred under reflux condenser (synthesis $\mathrm{A}$ ) or at static conditions in an oven (synthesis B),

- post-synthesis grafting of organosilanes was performed in dry toluene on mesoporous support (A or B) calcined $\left(550^{\circ} \mathrm{C}\right.$ for $6 \mathrm{~h}$ ) and dried $\left(200^{\circ} \mathrm{C}\right.$ for $\left.2 \mathrm{~h}\right)$ directly prior the grafting procedure.

Full names of the organosilanes containing functional groups (AcAc, AmPy, AmS, AmBenS) and the substrates used in their synthesis are given in Table S1 in Supplementary material.

The sizes of the mesopores and of the ligands were the criteria considered in the course of the materials preparation. Small ligand, acetylacetone (AcAc), was grafted onto the sample with the largest mesopores, nonetheless having high volume of micropores (SBA-15, sample B). This material (B) was also used as a support for a several ligands, in order to evaluate the influence of the ligands size on the grafting efficiency. The sample characterized with small mesopores (SBA-15, sample A) was used for grafting of two silanes containing the largest ligands (2-aminobenzothiazole (AmBenS), 2-aminopyridine (AmPy)). AmPy ligand was also anchored in triplicate on the support B to further study the role of diffusional limitations. The synthesis strategy was illustrated in Fig. S1. (Supplementary material). The following materials were used in the current work: acetylacetone, 2- aminopyridine, 2-aminothiazole grafted on the mesoporous silica B (BAcAc, BAmPyIII, BAmS, respectively) and 2-aminobenzothiazole grafted on the silica A (AAmBenS).

\subsection{Characterization methods}

The structure of the materials was characterized by X-ray powder diffractometer (BRUKER D2 PHASER) equipped with a CuKa radiation source. UV-Vis-DRS spectra were recorded on an Evolution 600 (Thermo Scientific) spectrophotometer, Fourier transform infrared spectra (FTIR) - Nicolet 6700 (Thermo Scientific) FT-IR spectrometer using ATR technique, while the percentage content of carbon, nitrogen and sulfur in the samples was determined by elemental analysis using a CHNS Vario MICRO Cube microanalyzer.

Thermoporometry (TPM) analyses were performed using Mettler Toledo apparatus DSC $822^{\mathrm{e}}$, with the accuracy of $4.10^{-6} \mathrm{~W}$, equipped with a liquid nitrogen cooling system (Criofab). Before the TPM experiment the samples were placed in aluminum pans, water was added and the pans were sealed with lids. To avoid the super-cooling effect, the samples were quenched far below the equilibrium freezing temperature (to $-30{ }^{\circ} \mathrm{C}$ ) with the cooling rate $\beta=10 \mathrm{~K} \mathrm{~min}^{-1}$ and then heated with $\beta=2 \mathrm{Kmin}^{-1}$ up to $10^{\circ} \mathrm{C}$ [23]. After the experiment, a small hole was made in the lids of the crucibles and the samples were heated to $200{ }^{\circ} \mathrm{C}$ to evaporate the liquid component and the samples masses measured. Pore size distribution was determined from the solid to liquid DSC profiles. The melting point depression was obtained relative to the excess phase, so that each experiment was internally calibrated for temperature [24].

\subsection{Adsorption studies}

The hybrid adsorbent having the most confined pores (AAmBenS) and the largest grafted ligand was used for the adsorption tests of all the studied molecules. It was expected that in such conditions the effect of adsorbent/adsorbate interactions would be the most intense and evident. For the remaining materials, besides $\mathrm{Cu}^{2+}$ salts, only one dye (AMB) was selected due to its industrial provenance. The adsorption experiments were carried out in polypropylene vessels by adding $25 \mathrm{mg}$ of the functionalized SBA- 15 to $10 \mathrm{~mL}$ of $1 \mathrm{mmol} \mathrm{L}^{-1}\left(63.5 \mathrm{mg} \mathrm{Cu}^{2+}\right.$ $\mathrm{L}^{-1}$ ) copper solution in a form of $\mathrm{CuCl}_{2} \cdot 2 \mathrm{H}_{2} \mathrm{O}$ or $\mathrm{Cu}\left(\mathrm{CH}_{3} \mathrm{COO}\right)_{2} \cdot \mathrm{H}_{2} \mathrm{O}$. To verify the effectiveness of organic dye capture adsorption tests with Methyl Orange (MO), Rose Bengal (RB), Congo Red (CR) and industrial Levafix Amber CA gran (AMB) were performed. Table 1 shows the structure of dyes, which have been used in adsorption tests, and their properties. The initial concentrations of the dyes solutions, were in the range of $16-50 \mathrm{mmol} \mathrm{L}^{-1}\left(50 \mathrm{mg} \mathrm{L}^{-1}\right)$. In this case, $10 \mathrm{mg}$ of the functionalized SBA-15, was mixed with $30 \mathrm{~mL}$ of the dye solution. The solutions of the dyes and $\mathrm{Cu}^{2+}$ were stirred at $25^{\circ} \mathrm{C}$ for $2.5 \mathrm{~h}$, then centrifuged and the concentrations of the adsorbates in the supernatant determined spectrophotometrically (Thermo Scientific, Evolution 220). Adsorption capacity and adsorption efficiency were calculated according to Eq. (1) and Eq. (2), respectively.

$Q_{e}\left[\mathrm{mg} \mathrm{g}^{-1}\right]$ - adsorbed amount of copper/dye:

$Q_{e}=\frac{V \times\left(C_{0}-C_{e}\right)}{m}$

$E_{a d s}[\%]$ - adsorption efficiency:

$E_{a d s}=\left(1-\frac{C_{e}}{C_{0}}\right) \times 100 \%$

where:

$\mathrm{V}[\mathrm{L}]$ - volume of the adsorbate solution, $C_{0}\left[\mathrm{mg} \mathrm{L}^{-1}\right]$ - initial adsorbate concentration,

$C_{e}\left[\mathrm{mg} \mathrm{L}^{-1}\right]$ - equilibrium adsorbate concentration, $\mathrm{m}[\mathrm{mg}]-$ mass of the adsorbent. 
Table 1

Comparison of molecular structures and physico-chemical properties of the studied dyes.

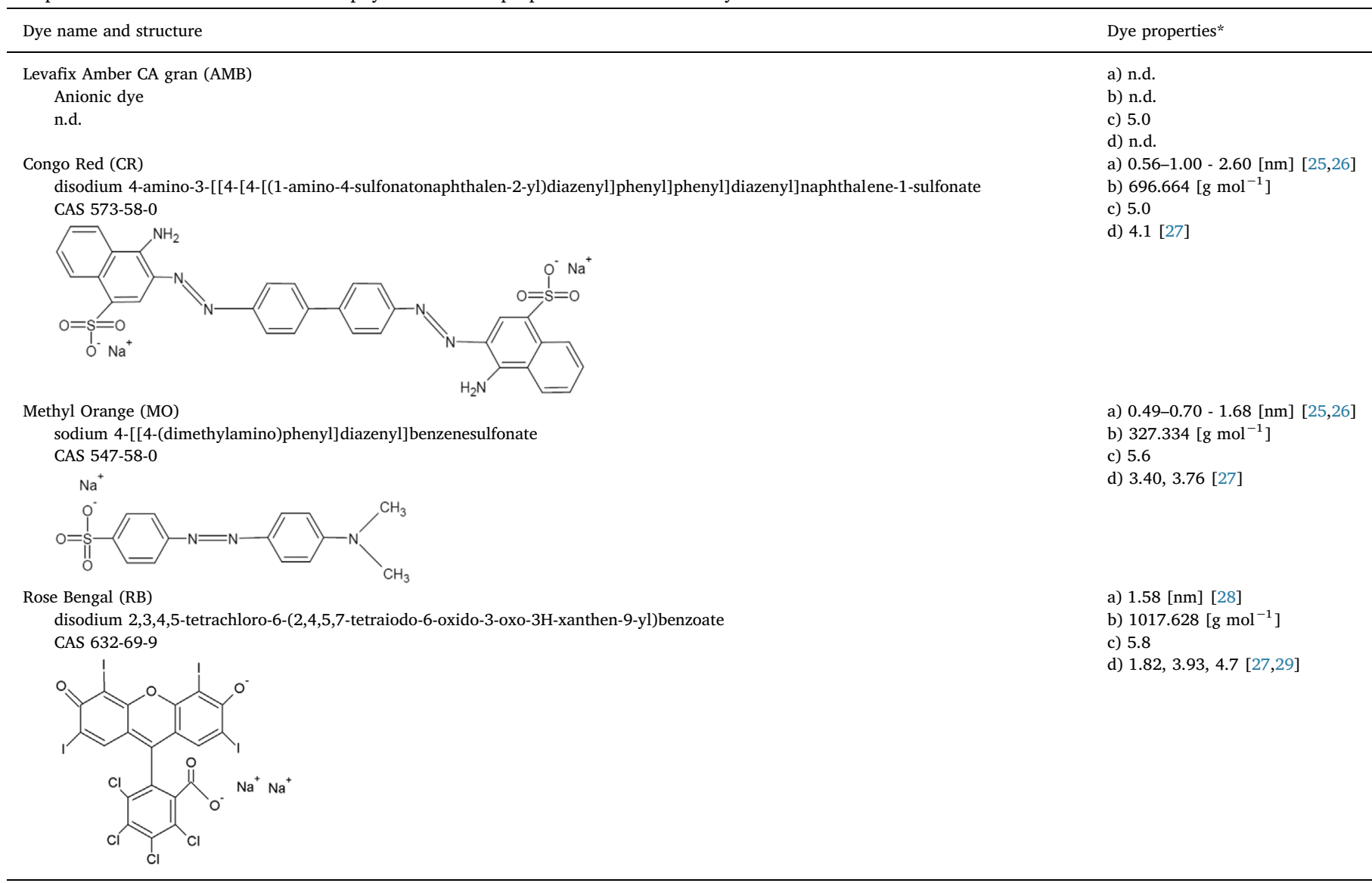

*a) dye dimensions, b) molecular weight, c) $\mathrm{pH}$ range of $50 \mathrm{mg} \mathrm{L}^{-1}$ solution, d) $\mathrm{pK}_{\mathrm{a}}$; n.d. - not disclosed.

$Q_{e}$ values were also expressed as $\mathrm{mmol} \mathrm{g}^{-1}$, allowing to estimate the percentage of functional groups involved in adsorption process (occupied functional groups) [\%].

\section{Results and discussion}

\subsection{Adsorption studies}

Dyes removal strongly depended on a type of the organic ligand and on the properties of the adsorbate molecule. Consequently, the adsorption efficiency could not be straightforward correlated with the surface ligands density. The acetylacetone (AcAc) modified sample showed negligible affinity for anionic organic pollutant AMB, while large ligands such as 2-aminopyridine (AmPy), 2-aminothiazole (AmS) and 2-aminobenzothaziole (AmBenS) exhibited moderate to high (up to $0.293 \mathrm{mmol} \mathrm{g}^{-1}$ ) adsorption levels with respect to the values reported in the literature for similar materials (Table 2). The studies performed on AAmBenS using dyes of different charge and geometry (MO, RB, CR, $A M B)$, proved that the adsorbate's properties determined adsorption efficiency. In this case, the number of ligands occupied by adsorbed molecules varied from 5 to $42 \%$.

The amount of the adsorbed $\mathrm{Cu}^{2+}$ ions changed from 1.5 to $13.6 \mathrm{mg} \mathrm{g}^{-1}$ and from 3.9 to $38.6 \mathrm{mg} \mathrm{g}^{-1}$, when chloride or acetate copper(II) salt was used in the experiment, respectively (Table 2). The most effective $\mathrm{Cu}^{2+}$ removal was on the aminothiazole modified material (BAmS), while on the aminopyridine modified one (BAmPyIII) it reached the lowest level. The materials differed slightly in terms of the grafted ligands density, therefore, calculated percentage of the occupied functional groups varied between 3 and 52\%. The obtained adsorption capacities are in accordance with the ones reported in the literature for organomodified silicas, although no $\mathrm{pH}$ adjustment, that could enhance the adsorption capacities of metal cations, was used in presented work to avoid the interference of background substances with ligands and adsorbed molecules.

Interactions of the AcAc modified silica with copper(II) salts lead to adsorption of $\mathrm{Cu}^{2+}$ cations through formation of chelated copper(II) complexes with acetoacetone structural unit. The adsorption of $\mathrm{Cu}^{2+}$ strongly depended on the copper(II) salt used in the experiment copper(II) acetate was much more effective reagent than copper(II) chloride. The differences can be due to interaction of AcAc structural unit with acetate and chloride anions. Acetoacetone ligand is a weak acid which undergoes a deprotonation and creates reactive enolate. Acetate anion is the conjugate base to a weak acetic acid and its basicity is enough to deprotonate any acid with a pKa below 5 . In the presence of acetate anions the equilibrium between $\beta$-diketone and its enolate form is shifted and the concentration of enolate increases. As a consequence, chelation of the $\mathrm{Cu}^{2+}$ cations is more efficient. In contrast to acetate anions, chloride anions are weaker base and their impact on enolization of AcAc ligand seems to be negligible.

On the other hand, the ligands such as 2-aminothiazole, 2-aminobenzothiazole and 2-aminopyridine are basic, they do not show $\mathrm{CH}$-acid properties. They can be protonated and thus inactivated for the chelation reaction. In this case the role of $\mathrm{CH}_{3} \mathrm{COO}^{-}$anions could be to increase the basicity of the reaction environment by capturing of free $\mathrm{H}^{+}$ ions. Free protons resulting from dissociation of $\mathrm{Si}-\mathrm{OH}$ fragments may be consecutively hindering chelation of metal cations due to protonation of $\mathrm{N}$ atoms in ligands. 
Table 2

Adsorption capacity of pollutants $\left(\mathrm{Q}_{\mathrm{e}}\right)$, adsorption efficiency $\left(\mathrm{E}_{\mathrm{ads}}\right)$ and percentage of occupied functional groups.

\begin{tabular}{|c|c|c|c|c|}
\hline $\begin{array}{l}\text { Sample } \\
\text { (density of grafted ligands) } \\
\text { /adsorbate }\end{array}$ & $\begin{array}{l}\mathrm{Q}_{\mathrm{e}} \\
{[\mathrm{mmol}} \\
\left.\mathrm{g}^{-1}\right]\end{array}$ & $\begin{array}{l}\mathrm{Q}_{\mathrm{e}} \\
{[\mathrm{mg}} \\
\left.\mathrm{g}^{-1}\right]\end{array}$ & $\mathrm{E}_{\mathrm{ads}}[\%]$ & $\begin{array}{l}\text { Percentage of } \\
\text { occupied } \\
\text { functional } \\
\text { groups }^{\text {a }}[\%]\end{array}$ \\
\hline $\begin{array}{l}\text { BAcAc } \\
\qquad\left(0.81\left[\mathrm{mmol} \mathrm{g}^{-1}\right] ; 0.71\right. \\
\left.\left[\text { molecules } \mathrm{nm}^{-2}\right]\right) / \mathrm{CuCl}_{2}\end{array}$ & 0.039 & 2.5 & 5 & 5 \\
\hline$/ \mathrm{Cu}\left(\mathrm{CH}_{3} \mathrm{COO}\right)_{2}$ & 0.098 & 6.3 & 12 & 12 \\
\hline /AMB & $0.031^{\mathrm{b}}$ & 6.9 & 0.8 & 4 \\
\hline $\begin{array}{l}\text { BAmPyIII } \\
\qquad\left(0.65\left[\mathrm{mmol} \mathrm{g}^{-1}\right] ; 0.58\right. \\
\left.\left[\text { molecules } \mathrm{nm}^{-2}\right]\right) / \mathrm{CuCl}_{2}\end{array}$ & 0.024 & 1.5 & 4 & 4 \\
\hline$/ \mathrm{Cu}\left(\mathrm{CH}_{3} \mathrm{COO}\right)_{2}$ & 0.062 & 3.9 & 10 & 9 \\
\hline /AMB & $0.062^{\mathrm{b}}$ & 13.9 & 23 & 10 \\
\hline $\begin{array}{l}\text { BAmS } \\
\qquad\left(1.59-1.17^{\mathrm{c}}\left[\mathrm{mmol} \mathrm{g}^{-1}\right] ;\right. \\
1.40-1.04^{\mathrm{c}}[\text { molecules } \\
\left.\left.\mathrm{nm}^{-2}\right]\right) / \mathrm{CuCl}_{2}\end{array}$ & 0.214 & 13.6 & 13 & 13 \\
\hline$/ \mathrm{Cu}\left(\mathrm{CH}_{3} \mathrm{COO}\right)_{2}$ & 0.607 & 38.6 & 38 & $38-52^{c}$ \\
\hline /AMB & $0.293^{\mathrm{b}}$ & 65.0 & 46 & $20-27^{\mathrm{c}}$ \\
\hline $\begin{array}{l}\text { AAmBenS } \\
\qquad \begin{array}{l}\left(1.15-0.89^{\mathrm{c}}\left[\mathrm{mmol} \mathrm{g}^{-1}\right]\right. \\
0.81-0.63^{\mathrm{c}}\left[\mathrm{molecules}^{-}\right. \\
\left.\left.\mathrm{nm}^{-2}\right]\right) / \mathrm{CuCl}_{2}\end{array}\end{array}$ & 0.029 & 1.8 & 2 & 3 \\
\hline$/ \mathrm{Cu}\left(\mathrm{CH}_{3} \mathrm{COO}\right)_{2}$ & 0.087 & 5.5 & 7 & $8-10^{c}$ \\
\hline /AMB & $0.149^{\mathrm{b}}$ & 68.6 & 46 & $18-23^{\mathrm{c}}$ \\
\hline /RB & 0.044 & 43.1 & 29 & $5-7^{c}$ \\
\hline /CR & 0.099 & 64.3 & 43 & $11-14^{\mathrm{c}}$ \\
\hline /MO & 0.292 & 88.9 & 59 & $32-42^{c}$ \\
\hline
\end{tabular}

Reference materials

\begin{tabular}{|c|c|c|c|c|}
\hline $\begin{array}{l}\text { SBA-15 aminopropyl/ } \mathrm{Cu}^{2+} \\
\text { propyl ethylenediamine } / \mathrm{Cu}^{2+} \\
{[30]}\end{array}$ & $\begin{array}{l}0.82 \\
0.35\end{array}$ & $\begin{array}{l}52.1 \\
22.2\end{array}$ & $\mathrm{x}$ & $\mathrm{x}$ \\
\hline $\begin{array}{l}\text { SBA-16 cyclam mono-/ } / \mathrm{Cu}^{2+} \\
\text { di-/ } / \mathrm{Cu}^{2+} \\
\text { tetra-sylilated } / \mathrm{Cu}^{2+}[30]\end{array}$ & $\begin{array}{l}0.30 \\
0.13 \\
0.03\end{array}$ & $\begin{array}{l}19.1 \\
8.3 \\
1.9\end{array}$ & $\mathrm{x}$ & $\mathrm{x}$ \\
\hline $\begin{array}{l}\text { SBA-15 N-propylsalicylaldimine } \\
\qquad / \mathrm{Cu}^{2+}[30]\end{array}$ & 0.73 & 46.4 & $\mathrm{x}$ & $\mathrm{x}$ \\
\hline $\begin{array}{l}\text { G-N-SBA-15 }\left(0.75\left[\mathrm{mmol} \mathrm{g}^{-1}\right]\right) \\
\text { 3- } \\
\text { aminopropyltrimethoxysilane } \\
\text { /Bromothymol Blue [22] }\end{array}$ & 0.019 & 12.0 & $\mathrm{x}$ & $\mathrm{x}$ \\
\hline $\begin{array}{l}\text { G-NN-SBA-15 }\left(0.62\left[\mathrm{mmol} \mathrm{g}^{-1}\right]\right) \\
\text { [1-(2-aminoethyl)- } \\
\text { 3aminopropyl]- } \\
\text { trimethoxysilane } \\
\text { /Bromothymol Blue [22] }\end{array}$ & 0.021 & 12.9 & $\mathrm{x}$ & $\mathrm{x}$ \\
\hline $\begin{array}{l}\left.\text { G-NNN-SBA-15 (0.58 [mmol g }{ }^{-1}\right] \text { ) } \\
\text { 1-[3-(trimethoxysilyl)- } \\
\text { propyl]-diethylenetriamine } \\
\text { /Bromothymol Blue [22] }\end{array}$ & 0.022 & 13.7 & $\mathrm{x}$ & $\mathrm{x}$ \\
\hline $\begin{array}{l}\text { SBA-15 } \\
\text { 3-aminopropyltriethoxysilane } \\
\quad\left(3.67\left[\mathrm{mmol} \mathrm{g}^{-1}\right]\right) \\
\text { /Reactive Blue-15 [21] }\end{array}$ & 0.064 & 80.3 & $\mathrm{x}$ & $\mathrm{x}$ \\
\hline $\begin{array}{l}\text { SBA-15 } \\
\text { triethylenetetramine }(0.61 \\
\left.\left[\mathrm{mmol} \mathrm{g}^{-1}\right]\right) \\
\text { /Reactive Blue-15 [21] }\end{array}$ & 0.072 & 90.4 & $\mathrm{x}$ & $\mathrm{x}$ \\
\hline $\begin{array}{l}\text { amino ethyl-functionalized } \\
\text { SBA-15 [31] } \\
\text { /Acid Red } 37 \mathrm{pH} \text { acidic }\end{array}$ & 0.648 & 333.3 & $\mathrm{x}$ & $\mathrm{x}$ \\
\hline
\end{tabular}

a Assuming ligand:adsorbate binding molar ratio equal 1:1.

b Based on elemental analysis.

c With respect to nitrogen (first value) or sulfur (second value) content.

\section{2. $X R D$}

The X-ray powder diffraction analyses (results shown in Fig. S2 in Supplementary material) confirmed formation of well-ordered mesoporous silica matrix. The materials' stability after grafting and adsorption process was higher in the samples obtained from the silica aged in static conditions. This can be explained by the fact that stirring applied in aging process have influenced not only rod-like particle diameter, but also particles morphology (defect dominated), apparently rendering the material more susceptible to structural changes [32-34]. In the spent materials the hexagonal mesostructure was preserved.

\subsection{FTIR}

In comparison to the starting compounds (Fig. 1.), the silica sample modified with AcAc, exhibited bands at 1700 and $1358 \mathrm{~cm}^{-1}$ assigned to the stretching vibration of $\mathrm{C}=\mathrm{O}$ group and in-plane bending vibration of $-\mathrm{CH}_{3}$ groups, respectively, that shifted to 1694 and $1363 \mathrm{~cm}^{-1}$ after grafting. Further shift of the bands to 1690 and $1377 \mathrm{~cm}^{-1}$ and significant decrease in the bands' intensity occurred due to formation of chelating complex with adsorbed $\mathrm{Cu}^{2+}$ cations.

In all modified samples, the band of a free silanol groups band at $3747 \mathrm{~cm}^{-1}$ disappeared although the bands corresponding to the stretching in H-bonded water, scissor bending vibration of molecular water, a superimposition of various $\mathrm{SiO}_{2}$ bands, $\mathrm{Si}-\mathrm{OH}$ bonding or $\mathrm{Si}-\mathrm{O}$ stretching vibrations and finally two stretching vibrations of Si-O-Si, in the range of $3640-3000,1628,1248,1090$ and $1037 \mathrm{~cm}^{-1}$, respectively, remained unaltered [35-37]. The bands attributed to the asymmetric vibrations of $\mathrm{Si}-\mathrm{OH}\left(975 \mathrm{~cm}^{-1}\right)$ and symmetric stretching vibrations of Si-O-Si $\left(812 \mathrm{~cm}^{-1}\right)$ were observed at 955 and $803 \mathrm{~cm}^{-1}$, respectively, after the grafting process. Further reorganization of the $\mathrm{Si}$ $\mathrm{OH}$ and Si-O-Si vibrations occurred when $\mathrm{Cu}^{2+}$ cations were added: the band at $1248 \mathrm{~cm}^{-1}$ nearly disappeared, alike the bands corresponding to the modes of molecular water, while stretching vibrations of silica were represented by bands at 1045, 957 and $796 \mathrm{~cm}^{-1}$ (Fig. 1). There was no difference between FTIR spectra recorded after adsorption of $\mathrm{Cu}^{2+}$ cations from different salts solutions (acetate and chloride).

Unlike with AcAc, functionalization of the SBA-15 with the other silanes (AmPy, AmS, AmBenS) resulted in a decrease of the bands intensity assigned to hydroxyl groups straightway upon grafting, furthermore the FTIR spectra remained the same after adsorption. The bands corresponding to water, if present after adsorption, were shifted to lower wavenumbers in the range of $3400-3250$ and $1620 \mathrm{~cm}^{-1}$. The lower content of water molecules in the materials modified with large organic ligands may be due to their more hydrophobic nature in comparison to acetylacetone.

The bands assigned to vibrations of the $-\mathrm{CH}_{2}$ and $\mathrm{Si}-\mathrm{OCH}_{2}$ groups were observed in the range of $2975-2850 \mathrm{~cm}^{-1}$ and had low intensity. However, the bands attributed to vibrations of the $\mathrm{C}=\mathrm{O}$ and aromatic $\mathrm{C}=\mathrm{N}$ groups and bending of the $\mathrm{N}-\mathrm{H}$ group, specific for the incorporated organofunctional groups and usually observed in the range of $1680-1400 \mathrm{~cm}^{-1}$, were less numerous and much broader than in the starting organosilanes or overlapped by silica's characteristic bands. This could indicate a heterogeneous orientation of the grafted molecules. The lack of changes in the spectra after adsorption indicates that interaction with the adsorbed molecules did not alter the grafted groups incorporated into the structure of the SBA-15, hence the materials were stable under experimental conditions.

\subsection{TPM}

Porosity determination of organomodified mesoporous silicas reported so far in the literature is based on low temperature $\mathrm{N}_{2}$ adsorption [e.g. Ref. [38]] and does not reflect real conditions in adsorbate-adsorbent systems. Nitrogen adsorption requires high vacuum and preferably elevated temperature to remove volatile compounds from the materials' structure to allow reliable measurement of the relative pressure. On the other hand, water thermoporometry (TPM) was reported as an alternative method for porosity characterization of hydrophilic materials, and it may be used on samples in their hydrate state 

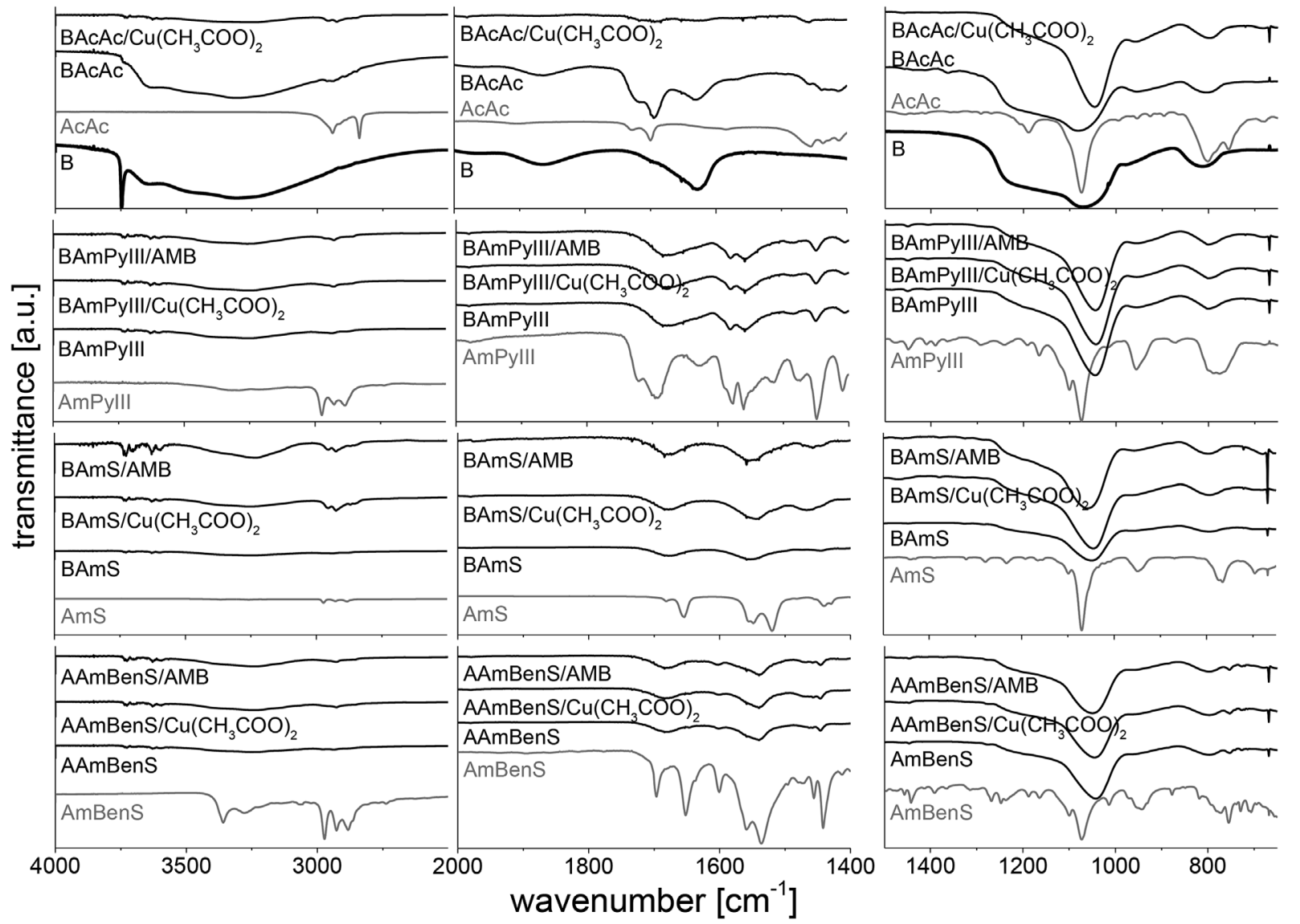

Fig. 1. FTIR spectra of pure SBA-15 (B), silanes with ligands (AcAc, AmPy, AmS, AmBenS), modified silica samples: before (BAcAc, BAmPyIII, BAmS, AAmBenS) and after $\left(\mathrm{BAcAc} / \mathrm{Cu}\left(\mathrm{CH}_{3} \mathrm{COO}\right)_{2}, \mathrm{BAmPyIII} / \mathrm{Cu}\left(\mathrm{CH}_{3} \mathrm{COO}\right)_{2}, \mathrm{BAmPyIII} / \mathrm{AMB}, \mathrm{BAmS} / \mathrm{Cu}\left(\mathrm{CH}_{3} \mathrm{COO}\right)_{2}, \mathrm{BAmS} / \mathrm{AMB}, \mathrm{AAmBenS} / \mathrm{Cu}\left(\mathrm{CH} \mathrm{COO}_{2}, \mathrm{AAmBenS} / \mathrm{AMB}\right)\right.$ pollutant $\left(\mathrm{Cu}^{2+}, \mathrm{AMB}\right.$ dye $)$ adsorption.

without affecting their pores' structure [23,24]. SBA-15 is known to be rather hydrophobic, however as it contains abundant surface silanol groups, that can interact with water molecules, it can adsorb large amounts of water by capillary condensation, even up to $0.84 \mathrm{gg}^{-1}$ [39]. Despite the moderate hydrophobicity of SBA-15, TPM was found a good method of studying the porosity of this group of mesoporous silicas $[40,41]$. Moreover, after functionalization the surface may became more hydrophilic making the method even more adequate for the pores characterization [42]. The TPM results were shown in Table 3. They were obtained with use of the previously established calibration equations [23].

Synthesis of SBA-15 at different aging conditions, stirred in flask under reflux condenser (synthesis A) or in static conditions in oven (synthesis B), resulted in materials of varying pores' sizes and pores' volumes.

After deposition of AcAc and calcination (BAcAc $\mathrm{C}_{\text {calc }}$ ) the pores' size remained unchanged, suggesting unsuccessful incorporation of the ligand (Table 3.). However, the measurements performed on the fresh sample in hydrated state (BAcAc) indicated a decrease in the pores' size by $0.4 \mathrm{~nm}$. Although acetylacetone molecule is relatively small $(0.7-0.8 \mathrm{~nm})$, pores' size reduction should be greater. Therefore, the grafting efficiency, calculated on the basis of elemental analysis (Table S2 in Supplementary material) and expressed as the density of grafted ligands $\left[\mathrm{mmol} \mathrm{g}^{-1}\right]$ (Table 2.), was low and the ligands' orientation was not perpendicular to the pores' walls surface. Grafting of the larger molecules (AmPy, AmS, AmBens) after calcination was reflected in a small pores' size reduction $(0.4 \mathrm{~nm})$ mainly due to incorporation of $\mathrm{Si}$ atoms into the silica wall. On the other hand, the presence of the original organic structures resulted in a decrease of the pores' diameter by $1.4 \mathrm{~nm}$ for 2-aminopyridine and 2-aminothiazole derivatives, and by
$1.9 \mathrm{~nm}$ in the case of 2-aminobenzothiazole. Those changes only roughly reflected an approximate length of the chelating groups, being equal $1.15 \mathrm{~nm}$ for AmPy or AmS and $1.45 \mathrm{~nm}$ in the case of AmBenS. Assuming perpendicular orientation of those three ligands, the expected size of pores filled with organic moieties should be much lower and equal 5.3, 5.2 and $3.8 \mathrm{~nm}$ for BAmPyIII, BAmS and AAmBenS, respectively. Therefore, tilted arrangement of the ligands, at the angle of about $50^{\circ}$, on the silica surface should be adopted as a model describing the studied materials (Fig. 2A.)

Adsorption of $\mathrm{Cu}^{2+}$ cations did not cause significant changes in the pores' size neither considering the studied ligands' properties nor the starting metal salt.

More prominent changes occurred upon dyes adsorption, however, a significant decrease in the pores' volume was observed only in the case of AMB adsorbed on AAmBenS. High adsorption capacity corresponded to the pore blocking by $\mathrm{CR}$ or AMB anions, especially in AAmBenS and BAmS materials. The pores' size distribution in the aforementioned spent materials was wider, thus the pores filling was more heterogeneous (Figs. 2B and 3).

Methyl Orange is a relatively small molecule with an ability to selfassembly what allowed it to easily enter between the organic ligands on the silica surface, hence, the adsorption capacity was high for this dye. Nonetheless, strong ligand-adsorbate interactions resulted in a close packing of the organic moieties and consequently widening of the pores' openings. Congo Red anions could be oriented either parallel to the pores' axis or interpenetrate the grafted ligands, with fragments of the molecule protruding into the pores' space. The lowest adsorption capacity, reported for Rose Bengal, was accompanied with a moderate decrease of the pores' size. Most probably steric obstacles hindered diffusion of bulky RB molecules between the grafted ligands and 
Table 3

Pores' size and volume obtained from TPM analysis.

\begin{tabular}{|c|c|c|}
\hline $\begin{array}{l}\text { Sample name } \\
\text { /adsorbate }\end{array}$ & Pore size $[\mathrm{nm}]$ & Pore volume $\left[\mathrm{mL} \mathrm{g}^{-1}\right]$ \\
\hline B & 7.6 & 0.57 \\
\hline $\mathrm{BAcAc}_{\mathrm{calc}^{*}}$ & 7.6 & 0.53 \\
\hline BAcAc & 7.2 & 0.39 \\
\hline$/ \mathrm{CuCl}_{2}$ & 7.1 & 0.38 \\
\hline$/ \mathrm{Cu}\left(\mathrm{CH}_{3} \mathrm{COO}\right)_{2}$ & 7.1 & 0.42 \\
\hline$/ \mathrm{AMB}$ & 7.0 & 0.41 \\
\hline BAmPyIII $_{\text {calc }} *$ & 7.2 & 0.42 \\
\hline BAmPyIII & 6.2 & 0.28 \\
\hline$/ \mathrm{CuCl}_{2}$ & 6.2 & 0.24 \\
\hline$/ \mathrm{Cu}\left(\mathrm{CH}_{3} \mathrm{COO}\right)_{2}$ & 6.1 & 0.22 \\
\hline$/ \mathrm{AMB}$ & 6.1 & 0.20 \\
\hline $\mathrm{BAmS}_{\mathrm{calc}^{*}} *$ & 7.2 & 0.52 \\
\hline BAmS & 6.2 & 0.26 \\
\hline$/ \mathrm{CuCl}_{2}$ & 6.2 & 0.28 \\
\hline$/ \mathrm{Cu}\left(\mathrm{CH}_{3} \mathrm{COO}\right)_{2}$ & 6.3 & 0.30 \\
\hline$/ \mathrm{AMB}$ & 5.8 & 0.26 \\
\hline A & 6.7 & 0.46 \\
\hline AAmBenS $_{\text {calc }} *$ & 6.3 & 0.37 \\
\hline AAmBens & 4.8 & 0.15 \\
\hline$/ \mathrm{CuCl}_{2}$ & 4.9 & 0.11 \\
\hline$/ \mathrm{Cu}\left(\mathrm{CH}_{3} \mathrm{COO}\right)_{2}$ & 4.8 & 0.13 \\
\hline$/ \mathrm{AMB}$ & 4.1 & 0.06 \\
\hline$/ \mathrm{RB}$ & 4.6 & 0.18 \\
\hline /CR & 4.1 & 0.13 \\
\hline /MO & 5.0 & 0.14 \\
\hline
\end{tabular}

*- organic ligands decomposed at $550{ }^{\circ} \mathrm{C}$.

adsorption occurred on top of the organic functional layer (Fig. 2A.).

\section{5. $U V$-Vis-DRS}

The peaks below $320 \mathrm{~nm}$ were assigned to the organic ligands: 2aminopyridine at 230 and $260-320 \mathrm{~nm}, 2$-aminothiazole and 2-aminobenzothiazole at around $250-315 \mathrm{~nm}$, and acetylacetone at 200, 250 and $310 \mathrm{~nm}$ (Fig. 4A. Fig. S3. Supplementary data). Therefore identification of the features belonging to the adsorbed molecules may be difficult. Nevertheless, the two peaks at around 240 and $280 \mathrm{~nm}$ in the spectra of BAmPyIII and BAcAc after $\mathrm{Cu}^{2+}$ adsorption could be assigned to the charge transfer $\mathrm{Cu}^{2+} \rightarrow \mathrm{O}$ [43]. Additionally, the broad bands at 630-655, 705, 715 and 710-720 nm (Fig. S3. Supplementary data) corresponding to the envelop of the three allowed DMSO- $d_{6}$ transitions [44], were observed in the spectra of copper complexes and AmS, AmBenS, AmPy and AcAc ligands, respectively. The peaks' positions are shifted hypsochromatically in comparison to the free complex probably due to a geometry change. One of the consequences of Jahn-Teller effect observed in the case of copper cations, is fast first-shell ligand exchange dynamics in the aqueous phase [45]. However, it was proposed that in solution neither the classical Jahn-Teller geometry nor other sixor fivefold-coordinated geometries may be proposed unambiguously as the single preferred structure of $\mathrm{Cu}^{2+}$ [46]. Another cause of the metachromacy may be stacking interactions between the ligands and copper complexes in which the complexes' electron cloud may be attracted toward a polar group of the ligand. This lowers the energy of highest occupied molecular orbital (HOMO) while empty and lowest unoccupied molecular orbital (LUMO) remains unaffected creating a higher energy difference between the orbitals and the transition occurs at higher energy thus at shorter wave length $[47,48]$. Nevertheless, it is

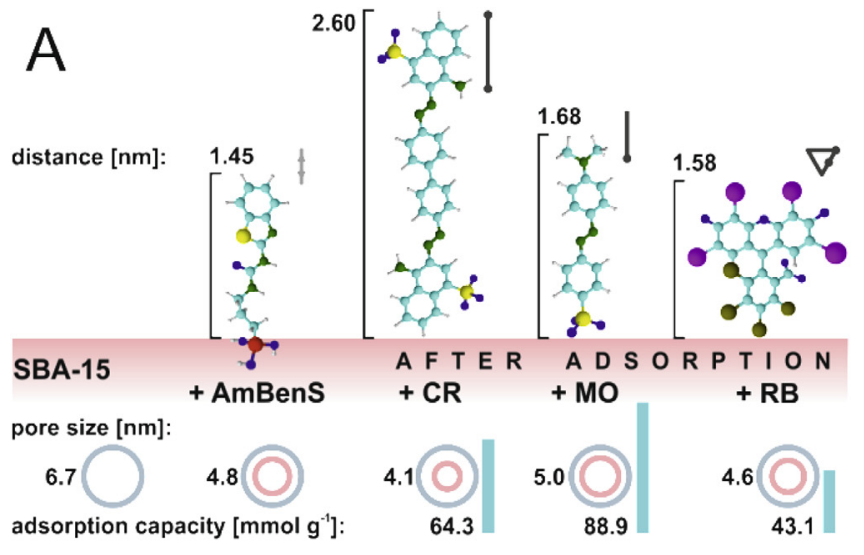

assumed molecules arrangement:

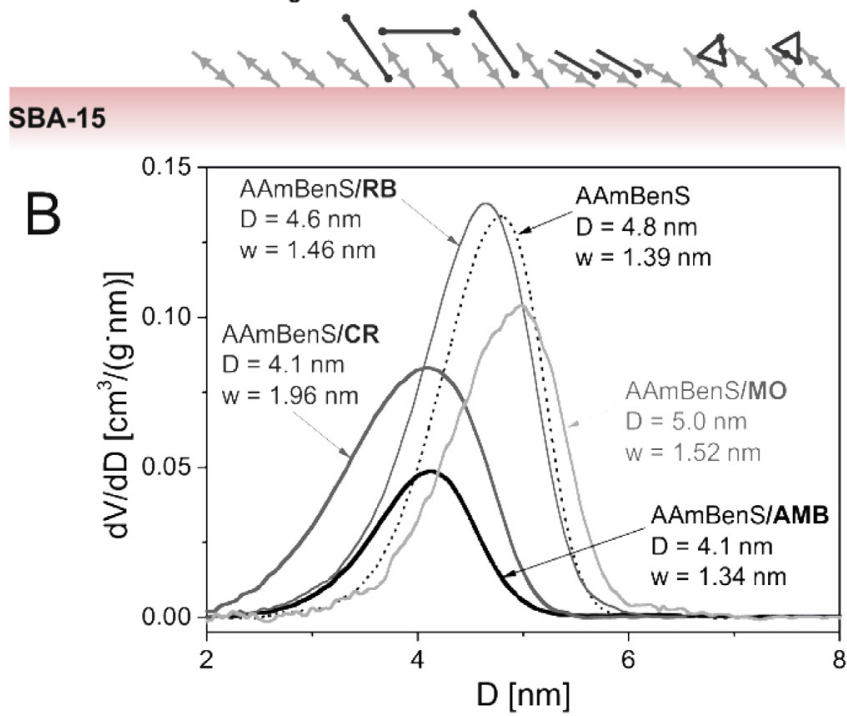

Fig. 2. Model of pore filling in SBA-15 upon grafting of organic ligand and adsorption of dyes molecules (A), pore size distribution of AAmBenS sample after dyes adsorption (B); D - maximum of pore size distribution, $\mathrm{w}$ - peak width.

clearly visible that band shift is correlated with metal cation adsorption capacity and formation of organic complexes.

In the samples with adsorbed AMB, the broad peak between 350 and $600 \mathrm{~nm}$ was assigned to the dye molecule. This dye was not efficiently adsorbed on BAcAc, thus the band for the studied molecule was very small. On the other hand, it was shown that remaining dyes (MO, CR, $\mathrm{RB}$ ) were successfully captured by modified silica AAmBenS. Exact peaks' positions and possible band splitting were determined using second derivative spectrum (Fig. 4B.). In the spectra of AMB, both blueand redshift was observed, while for other dyes only redshift occurred, additionally to the shifted peak for the spectrum of CR the original peak's position may be identified. Such phenomenon takes place for dye molecules as a result of aggregation [49].

In the case of Congo Red, the $498 \mathrm{~nm}$ band due to $\pi-\pi^{*}$ transition of azo group was bathochromically shifted to $542 \mathrm{~nm}$, whereas the $348 \mathrm{~nm}$ band arising from $\pi-\pi^{*}$ transition of $-\mathrm{NH}$ also undergone similar but less intense shift to $360 \mathrm{~nm}$ [50]. In the case of azo dyes the $\mathrm{H}$ aggregates can be formed via $\pi-\pi$ stacking, while the J-aggregates, may be obtained due to hydrogen bonding [51]. In the case of Methyl Orange (MO) the aggregation resulting in hypsochromic shift was due to the interactions between aromatic rings present in the structure of the dye ( $\pi-\pi$ stacking) and formation of dye J-aggregates (head-to-tail) [52]. Furthermore, Rose Bengal dye can form H-type aggregates in water and polar, protic solvents [53]. Similar effect, with blue shift due 


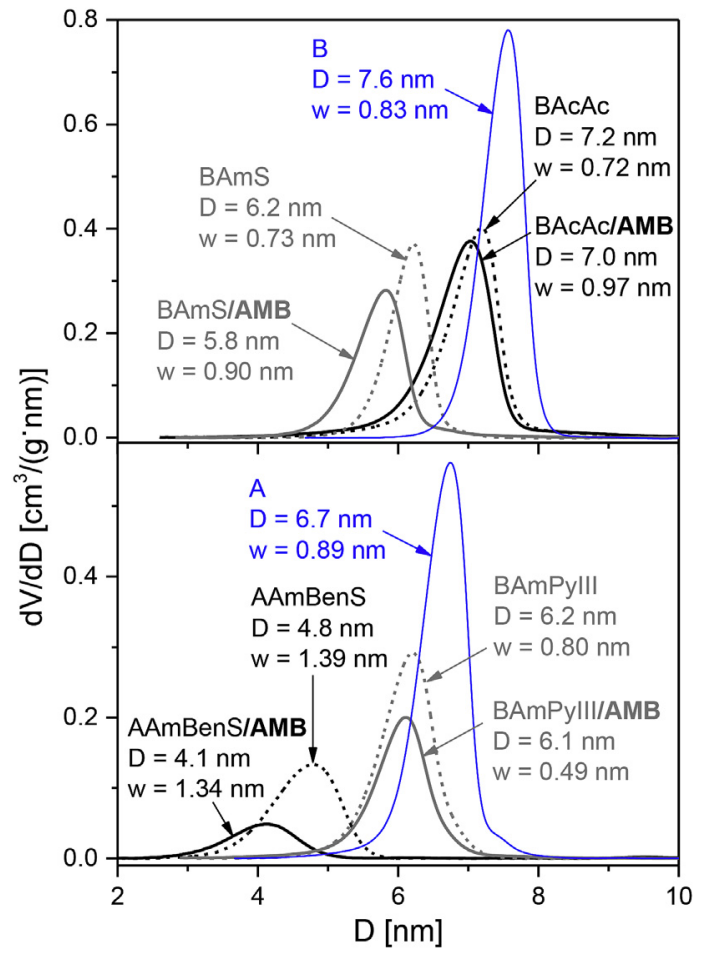

Fig. 3. Pore size distribution before and after adsorption of AMB dye on organofunctional silicas; D - maximum of pore size distribution, $\mathrm{w}$ - peak width.

to $\pi-\pi$ interactions of phenyl groups in MO, was described in confined spaces of anionic clays [54]. On the contrary to MO anions, which were tightly organized perpendicular to the clay layers, AMB and CR anions were tilted or flat lying in the interlayers but still a hypsochromic shift of the absorption maximum was observed. Therefore, in the case of the

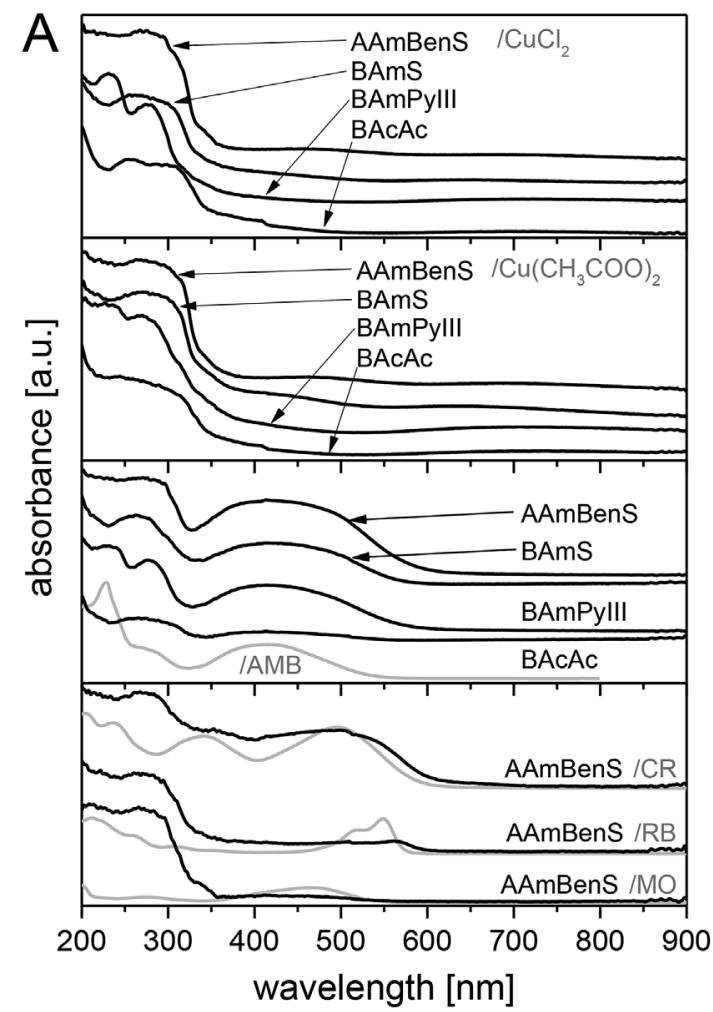

studied dyes adsorbed on organo-modified silicas, side-by-side positioning of aromatic rings or hydrogen bonding resulting in formation of the J-aggregates are preferred over face-to-face alignment typical for the H-aggregates [51]. The presence of both types of red- and blueshifted peaks for adsorbed AMB, suggest smaller size of the molecule and higher possibility of rearrangement inside of the SBA-15 pores.

Finally, interaction between AmPy, AmS and AmBenS modified silica and anionic dyes via electrostatic attraction should not take place. The pKa values for the substrates used in syntheses are equal to 6.28, 5.63 and 4.51 for 2-aminopyridine, 2-aminothiazole and 2-aminobenzothiazole, respectively, and they are expected to decrease upon imine formation after reacting with silane. Therefore, in selected conditions for adsorption experiment $(\mathrm{pH} \sim 5)$ functional groups should not be protonated.

\section{Conclusions}

Well-ordered mesoporous silica SBA-15 with incorporated organofunctional ligands was shown to be a stable adsorbent of copper cations and anionic dyes under investigated experimental conditions. The studied materials exhibited moderate to high adsorption capacities compared to the data available in the literature. The best results were obtained for removal of a dye Methyl Orange and an industrial dye Levafix Amber CA gran. The arrangement of the organic ligands and of the adsorbed molecules within SBA-15 mesopores was determined. It was found that the arrangement of the ligands was tilted, adsorbed copper cations did not influence materials' porous structure, but significant variations were observed for the dyes. For the first time it was determined by means of thermoporometry how ligands and adsorbed molecules are arranged within modified SBA-15 mesopores. Methyl Orange presented strong ligand-adsorbate interactions widening the pores' openings, while Levafix Amber CA gran and Congo Red caused pore blocking. $\mathrm{Cu}^{2+}$-ligand complexes were formed with distorted metal cation structure, whereas J-aggregates were dominating forms of

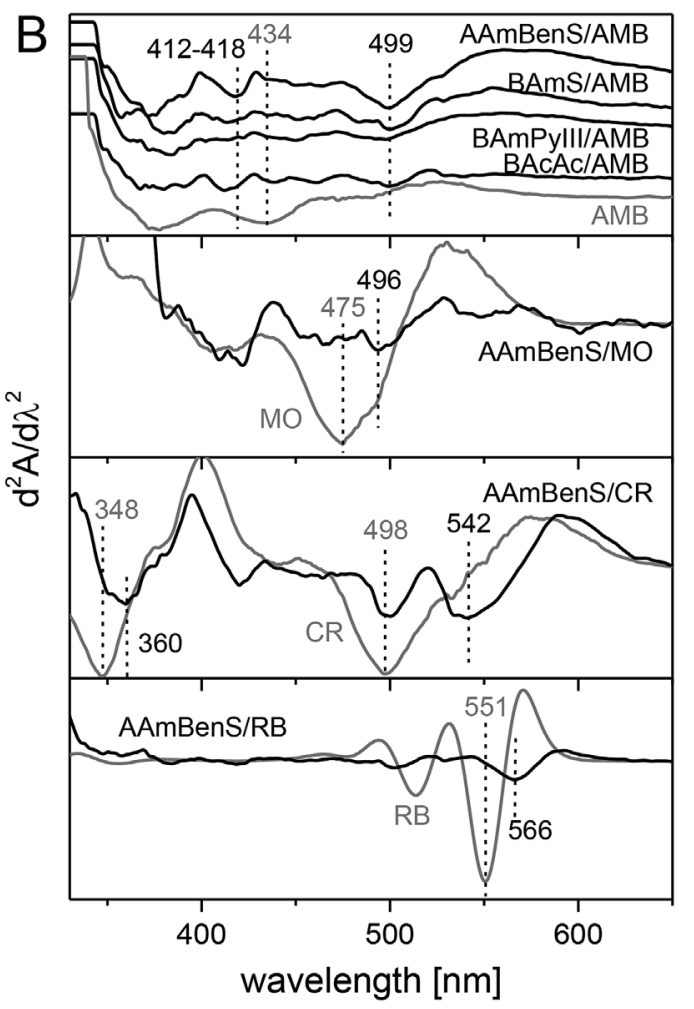

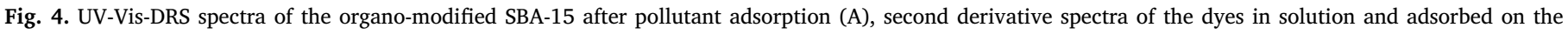
modified silicas (B); grey curves - spectra of pure adsorbates. 
interaction between dyes and grafted molecules.

The efficiency of adsorption of metal cations and organic dyes in model wastewaters depended on the type and number of anchored ligands in the SBA-15 as well as on the nature of the ligand-adsorbate interaction. Further studies based on the understanding of interactions between model pollutants and adsorbents, e.g. influence of solutions' $\mathrm{pH}$ changing protonation state of the organic ligands, are required for design and application of efficient hybrid adsorptive materials containing tailor made large chelating ligands.

\section{Acknowledgements}

Part of the research was carried out with the equipment purchased thanks to the financial support of the European Regional Development Fund in the framework of the Polish Innovation Economy Operational Program (contract no. POIG.02.01.00-12-023/08) and within the scope of the project of Labóratorio Associado para Química Verde Technologia e Processos Limpos - UID/QUI/50006, is financed by national founds of FCT/MEC and co-financed by Fundos FEDER (POCI-010145-FEDER-007265) within the scope of the partnership agreement PT2020. To all financing sources the authors are greatly indebted.

\section{References}

[1] L. Giraldo, J.C. Moreno-Piraján, Mater. Res. 16 (2013) 745-754.

2] P. Lipp, F. Sacher, G. Baldauf, Destilation Water Treat. 13 (2010) 226-237.

[3] H.M. ApSimon, P.A. Stott, H. van Dop (Ed.), Air Pollution Modeling and its Application VII, Springer US, Boston, MA, 1989, pp. 205-212.

[4] G. Vijayakumar, R. Tamilarasan, M. Dharmendirakumar, J. Mater. Environ. Sci. 3 (2) (2012) 157-170.

[5] H.A. Hegazi, HBRC J. 9 (3) (2013) 276-282.

[6] W. Stawiński, O. Freitas, L. Chmielarz, A. Węgrzyn, K. Komędera, A. Błachowski, S. Figueiredo, Chemosphere 153 (2016) 115-129.

[7] M.A. Barakat, Arab. J. Chem. 4 (4) (2011) 361-377.

[8] K. Nakagawa, A. Namba, S.R. Mukai, H. Tamon, P. Ariyadejwanich, W. Tanthapanichakoon, Water Res. 38 (7) (2004) 1791-1798.

[9] S. Wang, Y. Boyjoo, A. Choueib, Z.H. Zhu, Water Res. 39 (1) (2005) 129-138.

[10] W. Stawiński, A. Węgrzyn, T. Dańko, O. Freitas, S. Figueiredo, L. Chmielarz, Chemosphere 173 (2017) 107-115.

[11] W. Stawiński, A. Węgrzyn, O. Freitas, L. Chmielarz, G. Mordarski, S. Figueiredo, Sci. Total Environ. 576 (2017) 398-408.

[12] J. Toufaily, B. Koubaissy, L. Kafrouny, H. Hamad, P. Magnoux, L. Ghannam, A. Karout, H. Hazimeh, G. Nemra, M. Hamieh, N. Ajouz, T. Hamieh, Cent. Eur. J. Eng. 3 (1) (2013) 126-134.

[13] Q. Tao, Z. Xu, J. Wang, F. Liu, H. Wan, S. Zheng, Microporous Mesoporous Mater. 131 (1) (2010) 177-185.

[14] B. Samiey, C.-H. Cheng, J. Wu, Mater. Corros. 7 (2014) 673-726.

[15] A.M. Liu, K. Hidajat, S. Kawi, D.Y. Zhao, Chem. Commun. 13 (2000) 1145-1146.

[16] L. Zhang, C. Yu, W. Zhao, Z. Hua, H. Chen, L. Li, J. Shi, J. Non-Cryst. Solids 353 (44) (2007) 4055-4061.

[17] Z. Wang, M. Wang, G. Wu, D. Wu, A. Wu, Dalton Trans. 43 (22) (2014) 8461-8468.

[18] E. Da'na, A. Sayari, Chem. Eng. J. 166 (1) (2011) 445-453.

[19] V. Hernández-Morales, R. Nava, Y.J. Acosta-Silva, S.A. Macías-Sánchez, J.J. Pérez-
Bueno, B. Pawelec, Microporous Mesoporous Mater. 160 (Supplement C) (2012) 133-142.

[20] Y. Wu, M. Zhang, H. Zhao, S. Yang, A. Arkin, RSC Adv. 4 (106) (2014) 61256-61267.

[21] F. Rehman, P.L.O. Volpe, C. Airoldi, J. Environ. Manag. 133 (Supplement C) (2014) 135-143.

[22] I.M. El-Nahhal, A.A.A. Shawesh, F.S. Kodeh, S. Kuhn, R. Hempelmann, J. Sol. Gel Sci. Technol. 77 (2) (2016) 386-395.

[23] D. Majda, M. Zimowska, K. Tarach, K. Góra-Marek, B.D. Napruszewska, A. Michalik-Zym, J. Therm. Anal. Calorim. 127 (1) (2017) 207-220.

[24] M.R. Landry, Thermochim. Acta 433 (1) (2005) 27-50.

[25] U. Costantino, N. Coletti, M. Nocchetti, G.G. Aloisi, F. Elisei, Langmuir 15 (13) (1999) 4454-4460.

[26] G. Tang, C., C., University of Illinois at Urbana-Champaign, 2007.

[27] R.W. Sabnis, Handbook of Biological Dyes and Stains: Synthesis and Industrial Applications, Wiley, 2010

[28] P. Wu, M. Imai, Desalination Water Treat. 51 (25-27) (2013) 5237-5247.

[29] V.R. Batistela, D.S. Pellosi, F.D. de Souza, W.F. da Costa, S.M. de Oliveira Santin, V.R. de Souza, W. Caetano, H.P.M. de Oliveira, I.S. Scarminio, N. Hioka, Spectrochim. Acta Mol. Biomol. Spectrosc. 79 (5) (2011) 889-897.

[30] A. Walcarius, L. Mercier, J. Mater. Chem. 20 (22) (2010) 4478-4511.

[31] L. Hajiaghababaei, S. Abozari, A. Badiei, P. Zarabadi Poor, S. Dehghan Abkenar, M.R. Ganjali, G. Mohammadi Ziarani, Iran. J. Chem. Chem. Eng. (Int. Engl. Ed.) 36 (1) (2017) 97-108.

[32] Q. Wang, Z. Wang, T. Zheng, X. Zhou, W. Chen, D. Ma, Y. Yang, S. Huang, Nano Res. 9 (8) (2016) 2294-2302.

[33] M.-C. Chao, C.-H. Chang, H.-P. Lin, C.-Y. Tang, C.-Y. Lin, J. Mater. Sci. 44 (24) (2009) 6453.

[34] T. Benamor, L. Vidal, B. Lebeau, C. Marichal, Microporous Mesoporous Mater. 153 (2012) 100-114.

[35] D. Badeva, F. Tran-Van, L. Beouch, C. Chevrot, I. Markova, T. Racheva, G. Froyer, Mater. Chem. Phys. 133 (2) (2012) 592-598.

[36] H. Sanaeishoar, M. Sabbaghan, F. Mohave, Microporous Mesoporous Mater. 217 (Supplement C) (2015) 219-224.

[37] Q. Hu, H. Suzuki, H. Gao, H. Araki, W. Yang, T. Noda, Chem. Phys. Lett. 378 (3) (2003) 299-304.

[38] H. Chaudhuri, S. Dash, A. Sarkar, J. Environ. Chem. Eng. 3 (4, Part A) (2015) 2866-2874.

[39] E.-P. Ng, S. Mintova, Microporous Mesoporous Mater. 114 (1) (2008) 1-26.

[40] L.C. Cides da Silva, G.L.B. Araújo, N.R. Segismundo, E.F. Moscardini, L.P. Mercuri, I.C. Cosentino, M.C.A. Fantini, J.R. Matos, J. Therm. Anal. Calorim. 97 (2) (2009) 701-704.

[41] J. Riikonen, J. Salonen, M. Kemell, N. Kumar, D.Y. Murzin, M. Ritala, V.-P. Lehto, J. Phys. Chem. C 113 (47) (2009) 20349-20354.

[42] D. Majda, B.D. Napruszewska, M. Zimowska, W. Makowski, Microporous Mesoporous Mater. 234 (Supplement C) (2016) 98-106.

[43] F.M.T. Mendes, M. Schmal, Appl. Catal. Gen. 151 (2) (1997) 393-408.

[44] A.R. Silva, K. Wilson, A.C. Whitwood, J.H. Clark, C. Freire, Eur. J. Inorg. Chem. 2006 (6) (2006) 1275-1283.

[45] V.S. Bryantsev, M.S. Diallo, W.A. Goddard 3rd, J. Phys. Chem. B 112 (32) (2008) 9709-9719.

[46] J. Chaboy, A. Muñoz-Páez, P.J. Merkling, E.S. Marcos, J. Chem. Phys. 124 (6) (2006) 064509.

[47] M. Samuels, O. Mor, G. Rytwo, J. Photochem. Photobiol. B Biol. 121 (2013) 23-26.

[48] C. Dobrogowska, L.G. Hepler, D.K. Ghosh, S. Yariv, J. Therm. Anal. 37 (6) (1991) 1347-1356.

[49] H. Zollinger, Color Chemistry: Syntheses, Properties, and Applications of Organic Dyes and Pigments, Wiley, 2003.

[50] C. Debnath, A. Shil, S.A. Hussain, D. Bhattacharjee, Supramol. Chem. 29 (6) (2017) 401-410.

[51] K.K. Karukstis, L.A. Perelman, W.K. Wong, Langmuir 18 (26) (2002) 10363-10371.

[52] A.R. Petcu, E.A. Rogozea, C.A. Lazar, N.L. Olteanu, A. Meghea, M. Mihaly, Arab. J. Chem. 9 (1) (2016) 9-17

[53] D. Xu, D.C. Neckers, J. Photochem. Photobiol. Chem. 40 (2) (1987) 361-370.

[54] W. Stawiński, A. Węgrzyn, O. Freitas, L. Chmielarz, S. Figueiredo, Microporous Mesoporous Mater. 250 (2017) 72-87. 